\title{
The effect of multilingual policies on performance and progression in reading literacy in South African primary schools
}

\author{
Authors: Sarah Howie ${ }^{\mathrm{a}}$; Elsie Venter ${ }^{\mathrm{a}}$; Surette van Staden ${ }^{\mathrm{a}}$ \\ ${ }^{\text {a }}$ University of Pretoria, South Africa
}

\begin{abstract}
South Africa's rich multicultural society is reflected by 11 official languages. The Language in Education policy stipulates that children should start learning at school in their home language until Grade 3. In most schools, the language of instruction for all subjects changes in Grade 4 from an indigenous African language to English, which means that more than $80 \%$ of South African pupils learn in a language different to their home language. This paper seeks to ascertain (a) to what extent South African pupils are proficient readers in the language in which they have received reading instruction for 4 years, (b) what differences in achievement become evident between pupils in Grade 4 and Grade 5, and (c) the relationship between South African pupils' performance in the test language and home language. Statistics from the Progress in International Reading Literacy Study (PIRLS) 2006 were applied to determine differences in achievement.
\end{abstract}

\section{Introduction}

South Africa participated in the International Association for the Evaluation of Educational Achievement's (IEA) Progress in International Reading Literacy Study (PIRLS) for the first time in 2006. This was the most complex study conducted on reading literacy in South Africa to date and the most complex national study within an international comparative study where languages are concerned. While most countries participating in the study tested pupils at only one grade level, South Africa chose to test pupils in two grades: 4 and 5. The children, from just over 400 schools, were each assessed in one of South Africa's 11 official languages that was the language of the reading instruction they had received in Grades 1 to 3.

The National Department of Education's language policy stipulates that South African children receive instruction at school in their home language until they reach Grade 3. However, in the majority of schools, the language of instruction changes, and in Grade 4, more than 80\% of South African pupils learn in a second language, English or Afrikaans, whilst they also continue to receive reading instruction in the language of instruction of the first 3 years of schooling. The South African situation is complex because most White, Indian, and colored children continue to receive their schooling in the same language of instruction from Grades 1 to 12, namely English or Afrikaans. However, most children speaking African languages at home switch at Grade 4 to receive instruction in either English or Afrikaans, despite the current government 
language policy advocating learning to take place in their home language from Grades 1 to 12 .

PIRLS 2006 required that "(t)he target grade should be the grade that represents four years of schooling, continuing from the first year of ISCED Level 1" (Mullis, Kennedy, Martin, \& Sainsbury, 2006, p. 7). In South Africa, this definition translated into the Grade 4 level. Considering the fact that the language of instruction for the majority of children changes at Grade 4 level and that most of the vernacular languages are subsequently taught as a subject (and not necessarily the medium of instruction) from Grade 4 onwards, schools were sampled according to their medium of instruction during the first 3 years of schooling.

Already from the outset of PIRLS 2006, the level of reading required by the PIRLS assessment was deemed too high (by the National Research Centre and the National Steering Committee) for the South African Grade 4 cohort; therefore, it was decided also to include Grade 5 pupils. This inclusion enabled South Africa to detect differences in reading knowledge and skills from one grade to the next grade within one schooling phase.

The aim of this paper is to report on the proficiency of South African pupils' performance, their progress, and development in terms of their reading skills and knowledge from Grade 4 to Grade 5. Specifically, the variation in performance is explored in terms of test and home language. The paper therefore addresses the following research questions:

1. To what extent are South African Grade 4 pupils proficient readers in the language in which they have received reading instruction for the first 4 years of schooling as tested through the PIRLS 2006 assessment?

2. To what extent are there differences in performance between Grade 4 and 5 pupils in reading literacy?

3. What is the relationship between South African pupils' performance in reading literacy in the language of the test and their home language where these differ?

In order to answer the research questions, it is important to note that the underlying construct, reading literacy, is considered, and scaled scores on this continuum will be analyzed as general performance or proficiency, and not the influence of only certain items.

\section{Literature review}

The importance of literacy has become evident in the 50 years since the United Nations declared it to be a basic human right along with the right to adequate food, health care, and housing. Literacy education has indeed become a tool to help address what might be perceived to be more pressing needs for food, health care, and housing. Reading literacy is therefore not understood as a basic skill but rather as a goal. It is an important means of functioning effectively in education and of developing as an individual, within and outside school, today and in later life, in further education, at work, and in leisure activities (Linnakylä, Malin, \& Taube, 2004). 
The consequences for pupils who cannot read or who struggle to read in the early grades are well documented. Juel (1988; in Leslie \& Allen, 1999), reported that 88\% of the American Grade 4 children who scored in the lowest quartile for reading comprehension remained below the 50th percentile at the end of Grade 4.

In terms of reading performance, three aspects are a major influence: the home, the school, and the pupils themselves. Strickland, Ganske, and Monroe (2002) summarized what is known about successful readers and writers. Successful readers have normal to above average language skills and have opportunities to identify letters and environmental print. Children who become successful readers have exposure to adults who involve them in purposeful literacy experiences during the early childhood years. Successful readers are likely to attend schools that provide pupils with frequent and intensive opportunities to read and write, while building upon early childhood experiences with opportunities for pupils to learn the nature of the alphabetic system. Successful readers experience overall progress that is steady and sure, despite periodic difficulties, and in line with this have the ability to build on informal experiences with literacy from early years as they encounter more formal and complex tasks.

When it comes to what is known about pupils at risk of failure, Strickland et al. (2002) state that some factors pertain to the child's personal development and others to the group or situation they reside in. Children who are particularly at risk of encountering reading difficulties typically have a history of preschool language impairment, limited proficiency in English, or come from homes where a nonstandard dialect of English is spoken. Pupils at risk often have parents who had difficulty learning to read, they may come from poor neighborhoods, and they are likely to attend schools in which classroom practices are deemed ineffective. However, none of these factors is an automatic barrier to literacy, and none of them functions in isolation as a single causal factor of reading difficulties (Strickland et al., 2002).

The reality for most pupils in South Africa is one of reading and learning in a second language once they progress to Grade 4. Before Grade 4, the premise is that learning to read takes place in the children's mother tongue (or first language). Education policy aims to accommodate pupils' language needs by means of code-switching in the classroom, where teachers switch between English and the pupil's mother tongue. Howie (2003) reiterates that the South African education system has the challenge of providing quality education to a multicultural learner population, the members of which among them speak 11 different official languages. English as a first language is spoken by less than $10 \%$ of the population. As one of the languages most used by schools (the other being Afrikaans), English is not the most frequently spoken language at home. Thus, second language acquisition, mastery, and learning is a reality for the majority of pupils in South Africa. This language system is one of immersion, where a language that is not the language of the larger society is used as a medium of instruction (Admiraal, Westhoff, \& De Bot, 2006).

Second language pupils face two types of difficulties, namely inter-lingual learning problems caused by mother tongue interference, and intra-lingual learning problems, caused by the structure of the second language (Verhoeven, 1990). Children acquiring reading in a second language may experience difficulty with phonemic mapping, 
recognition of orthographic patterns, and direction recognition of words already represented in memory (Verhoeven, 1990). One hypothesis is that learning difficulties would be more pronounced in cases where the abovementioned recognition processes are absent, even for reading performance in mother tongue.

\section{Method}

This section describes the selected sample for which data were collected for PIRLS 2006 in South Africa (Martin, Mullis, \& Kennedy, 2007), followed by a description of the instruments used in the study and the data analysis procedures followed for this paper.

\section{Sample}

The South African sample for PIRLS 2006 consisted of 441 schools offering schooling at Grade 4 level. A proportional allocation was done firstly by province and subsequently by language of instruction in the first three grades from 15,182 schools. From this sample, Grade 5 pupils, where available, were also included in the study. The realized sample involved only data from 434 Grade 4 schools, and for Grade 5 it was 402 schools. The study generated achievement data for 16,057 Grade 4 pupils and 14,657 Grade 5 pupils, across nine provinces and 11 languages. Due to the probability sampling techniques used by PIRLS to sample pupils and the matrix sampling methods to administer only a subset of the PIRLS 2006 assessment to individual pupils, some uncertainty exists in the statistics. These two mentioned components contribute to the uncertainty of the performance estimates and are reflected by the calculated standard errors of the means (Martin et al., 2007). Therefore these standard errors are reported where the achievement results are presented in the paper.

\section{Instruments}

In South Africa, the PIRLS 2006 assessment took place in all 11 official languages in Grades 4 and 5, and contextual questionnaires were completed by learners (in all 11 languages), parents (the same language as their child plus an additional option of another language), teachers, and principals (in English). The raw scores from the PIRLS achievement instruments were transformed into scaled scores (see Martin et al., 2007). Great care was taken in the preparation stages of the study to determine and confirm the language of instruction of each class and that this language was in fact the language in which the children had been receiving instruction for the first 3 years of schooling. The terms test language and language of instruction are therefore used interchangeably in this paper. An English test was developed, in line with learning outcomes as stated in the Revised National Curriculum Statement, as a national option in South Africa and was administered in a rotated two-booklets design on a second day of testing to all pupils participating in PIRLS to gain some insight into pupils' reading skills in English as a second language. Although information about home language was sourced from this instrument, the national option as such is not the focus of this paper. 


\section{Data analysis}

The South African data from PIRLS 2006 that were collected and captured during the last part of 2005 and early 2006 are used in the data analysis. The average reading scores were (internationally) scaled with a mean of 500 and a standard deviation of 100.

To determine the normality of the data, a qq plot was constructed. The sample distribution of the variable "mean scale score" was found to be positively skewed (see the histogram in Figure 1), but normality is assumed for the purposes of this paper. The mean performance across test languages was considered and then the performance per grade in the 11 official languages. The final step was to look at the correspondence in performance, if any, between home language and test languages. Descriptive statistics and significance testing was undertaken in the analyses with the latter including $t$ tests. The software, the IEA International Database (IDB) analyzer (IEA, 2008) in conjunction with Statistical Package for Social Scientists (SPSS) was used permitting accurate generation of standard errors, which SPSS alone was unable to do given the nature of the sampling.

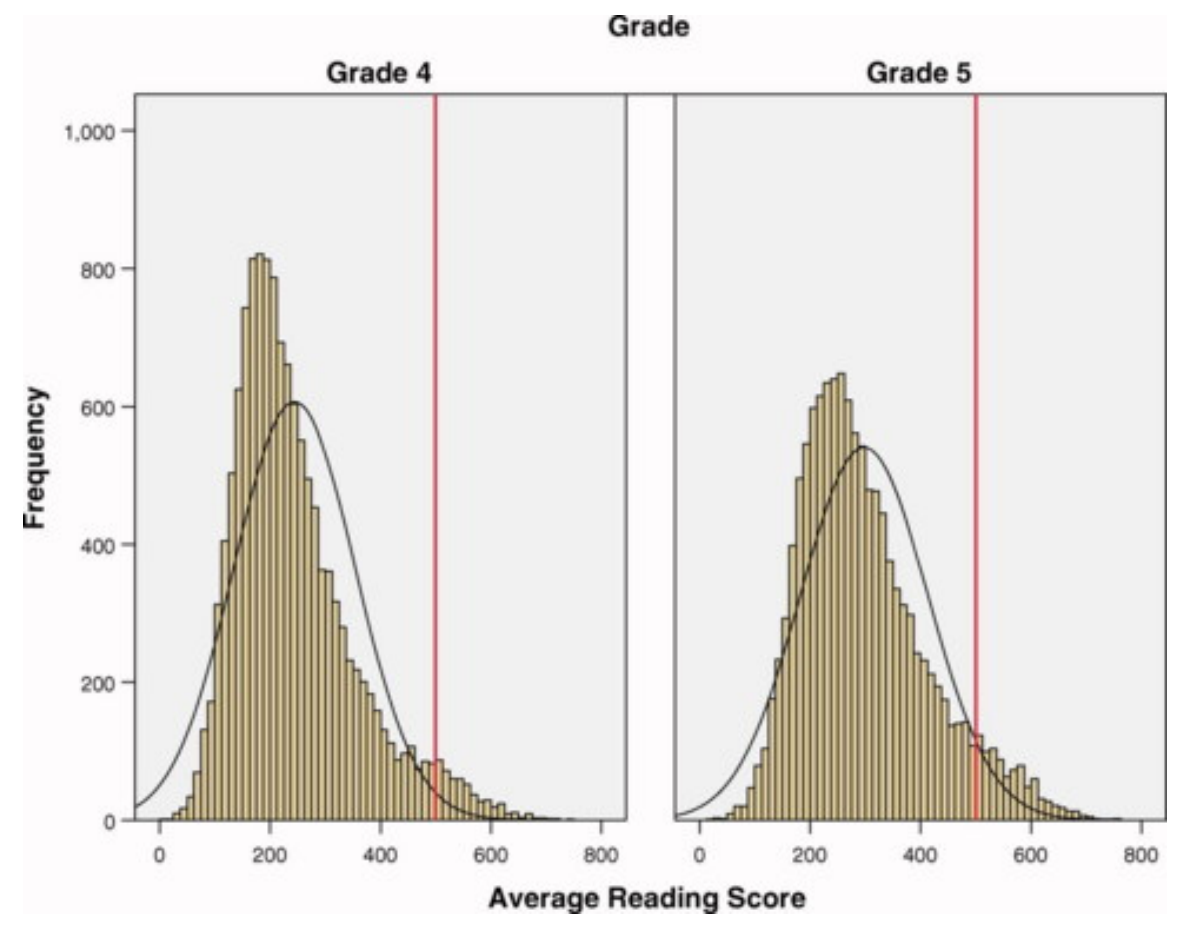

Figure 1. Histogram of reading performance for Grade 4 and Grade 5 South African pupils participating in PIRLS 2006.

\section{Results}

In this section, the results addressing the three questions posed earlier are presented. Firstly, the overall performance for Grade 4 and 5 is given, as well as an analysis per language of the test. Thereafter, the difference in performance between Grade 4 and 5 is tested. Finally, the relationship between the achievements of the children writing 
the test in their home language is compared to those writing in their second language (or third language).

\section{South African pupils' proficiency in reading}

The overall South Africa mean score in reading was 253 points $(S E=4.6)$ for Grade 4 pupils. The distribution of scores can be seen in Figure 1. The red vertical line is set at the International mean score of 500. For Grade 5, the mean is 302 points ( $S E=5.6$ ), as depicted in Table 1. In both grades, the South African performance is significantly below the international mean score and that of all other countries in the study.

Table 1. Descriptive and significance statistics for the national means for Grades 4 and 5 pupils.

\begin{tabular}{|c|c|c|c|c|c|}
\hline Grade & $N$ & Mean score & Std. Err. & $t$ value & Significance \\
\hline \multicolumn{6}{|c|}{ Note: *At a $5 \%$ level of significance. } \\
\hline 4 & 16,057 & 253 & 4.6 & \multirow{2}{*}{7.06} & \multirow{2}{*}{ Significant* } \\
\hline 5 & 14,657 & 302 & 5.6 & & \\
\hline
\end{tabular}

In terms of progress or development in reading between Grade 4 and 5, a $t$ test revealed a statistically significant difference of 49 points between the means of the two grades, with Grade 5 pupils achieving higher scores. As would be expected, an additional year's instruction makes a substantial difference in reading achievement. In terms of achievement in both grades across all 11 official languages, Table 2 presents the mean scores for each test language per grade. In all 11 languages tested, differences in achievement were evident from Grade 4 to Grade 5. The largest difference in reading achievement between Grade 4 and Grade 5 occurred in Afrikaans, with a difference of 79 points $(S E=22.7)$. Achievement in Sesotho and English were similar, with differences of $70(S E=10.4)$ and $65(S E=23.45)$, respectively, while isiXhosa showed the smallest difference in scores of 29 points $(S E=9.0)$. Results of all the $t$ tests revealed significant differences between Grade 4 and Grade 5 for each language, although in the case of isiXhosa, the value of 29 does not constitute any significance in an educational sense. As a group, the Nguni languages (isiNdebele, isiXhosa, isiZulu, and SiSwati) presented the smallest improvement. 
Table 2. Descriptive statistics for language used in test sat by Grades 4 and 5 pupils.

\begin{tabular}{|c|c|c|c|c|}
\hline Test Language & Grade & $N$ & Mean Score & Difference \\
\hline \multirow[t]{2}{*}{ Afrikaans } & 4 & 1,758 & 336 & 79 \\
\hline & 5 & 1,678 & 415 & \\
\hline \multirow[t]{2}{*}{ English } & 4 & 2,803 & 333 & 65 \\
\hline & 5 & 2,793 & 398 & \\
\hline \multirow[t]{2}{*}{ isiNdebele } & 4 & 831 & 176 & 62 \\
\hline & 5 & 798 & 238 & \\
\hline \multirow[t]{2}{*}{ isiXhosa } & 4 & 1,606 & 186 & 29 \\
\hline & 5 & 1,470 & 215 & \\
\hline \multirow[t]{2}{*}{ isiZulu } & 4 & 2,204 & 230 & 33 \\
\hline & 5 & 1,733 & 263 & \\
\hline \multirow[t]{2}{*}{ Sepedi } & 4 & 1,443 & 204 & 39 \\
\hline & 5 & 1,349 & 243 & \\
\hline \multirow[t]{2}{*}{ Sesotho } & 4 & 952 & 219 & 70 \\
\hline & 5 & 959 & 289 & \\
\hline \multirow[t]{2}{*}{ Setswana } & 4 & 1,163 & 252 & 36 \\
\hline & 5 & 1,055 & 288 & \\
\hline \multirow[t]{2}{*}{ SiSwati } & 4 & 1,339 & 208 & 41 \\
\hline & 5 & 1,147 & 249 & \\
\hline \multirow[t]{2}{*}{ Tshivenda } & 4 & 901 & 214 & 48 \\
\hline & 5 & 784 & 262 & \\
\hline \multirow[t]{2}{*}{ Xitsonga } & 4 & 1,057 & 223 & 54 \\
\hline & 5 & 891 & 277 & \\
\hline
\end{tabular}

\section{Home language versus language of instruction}

The correspondence between a pupil's home language and the language of the test was very important to investigate. The relationship between the South African pupils' performance in reading literacy in the language of the test when it was the same language or in a language different to their home language was also explored. The data under consideration have been constructed from the achievement data where the language of the test and the home language were known. 13,317 Grade 4 pupils complied with the above-mentioned requirement. In Grade 5, data for the home language were available for 12,457 pupils. In Grade 4, 74.5\% $(S E=1.56)$ of the pupils were assessed in their home language. In Grade 5, this percentage was similar at $74.3 \%(S E=1.61)$. One would expect a higher level of reading literacy when a pupil has access to language instruction in the same language as his or her home language. Table 3 presents the results of a $t$ test to ascertain the difference in performance at each grade between pupils for whom the home language and the test language corresponded and pupils for whom the home and test language differed. 
Table 3. Descriptive and significance statistics for same and for different languages for Grades 4 and 5 pupils.

Grade Language $N \begin{aligned} & \text { Mean Std. } t \\ & \text { score Err. value Significance* }\end{aligned}$

Note: *At a $5 \%$ level of significance.

\begin{tabular}{|c|c|c|c|c|c|c|}
\hline 4 & Same & 9,585 & 259 & 5.8 & \multirow{2}{*}{-0.61} & \multirow{2}{*}{$\begin{array}{c}\text { Nonsignifican } \\
\mathrm{t}\end{array}$} \\
\hline 4 & Different & 3,732 & 254 & 8.3 & & \\
\hline & Same & 8,997 & 306 & 6.6 & \multirow{2}{*}{0.48} & \multirow{2}{*}{ Nonsignificant } \\
\hline & Different & 3,460 & 311 & 9.6 & & \\
\hline
\end{tabular}

The difference between the two categories of pupils in the case of Grade 4 was -5.3, but for Grade 5 the difference was 4.8 . Both differences were statistically nonsignificant at the 0.05 level, with $t$ values of -0.61 and 0.48 , respectively. These overall figures, however, mask the significant differences that appear once one investigates the results per language grouping as seen below.

\section{Differences in performance between English, Afrikaans, and African language groupings}

The performance in the three test language groupings (English, Afrikaans, and the indigenous languages as a group, African languages) was compared in terms of mother tongue speakers and non-mother tongue speakers. All nine African languages were clustered into one group given the lack of variation in differences in scores between these languages.

Two groups of pupils were considered for each of the three test languages. For example, for English, Group 1 consisted of all pupils who indicated English as their home language and who wrote their answers to the test in English, whilst Group 2 constituted pupils who had a home language different to English but who wrote the test in English. To determine the statistical significance between the average performances of the groups, a $t$ test was performed and $t$ values obtained. This procedure was followed for Afrikaans and the indigenous group as well. Table 4 presents the results of the analyses per language grouping and for the significance testing. 
Table 4. Descriptive and significance statistics for whether languages pupils used in test were same as or different from home language.

\section{$\begin{array}{llllll}\text { Grade Language } \begin{array}{l}\text { Home vs Test } \\ \text { Language }\end{array} & N & \begin{array}{c}\text { Mean } \\ \text { score }\end{array} & \begin{array}{l}\text { Std. } \\ \text { Err. value }\end{array} & \text { Significance* }\end{array}$}

Note: *At a 5\% level of significance.

\begin{tabular}{|c|c|c|c|c|c|c|c|}
\hline \multirow[t]{2}{*}{4} & \multirow{4}{*}{ English } & Same & 619 & 458 & 18.9 & \multirow{2}{*}{-7.3} & \multirow{2}{*}{ Significant } \\
\hline & & Different & 1,820 & 284 & 13.1 & & \\
\hline & & Same & 559 & 513 & 13.6 & \multirow{2}{*}{-8.7} & \multirow{2}{*}{ Significant } \\
\hline & & Different & 1,817 & 349 & 14.7 & & \\
\hline & \multirow{4}{*}{ Afrikaans } & Same & 1,201 & 364 & 13.6 & \multirow{2}{*}{-3.3} & \multirow{2}{*}{ Significant } \\
\hline & & Different & 160 & 284 & 22.2 & & \\
\hline & & Same & 1,355 & 430 & 14.1 & \multirow{2}{*}{-3.7} & \multirow{2}{*}{ Significant } \\
\hline & & Different & 122 & 351 & 22.3 & & \\
\hline & \multirow{4}{*}{ African } & Same & 7,765 & 218 & 3.6 & \multirow{2}{*}{-1.0} & \multirow{2}{*}{ Nonsignificant } \\
\hline & & Different & 1,752 & 212 & 6.3 & & \\
\hline & & Same & 7,083 & 257 & 3.6 & \multirow{2}{*}{-1.4} & \multirow{2}{*}{ Nonsignificant } \\
\hline & & Different & 1,521 & 247 & 7.4 & & \\
\hline
\end{tabular}

The largest differences between the home language speakers and the other group were found amongst those pupils who wrote the assessment in English. A substantial difference was evident between pupils who were English mother tongue speakers and pupils who were English second language speakers. The difference in Grade 4 for the English assessment was -174.1 (SE = 23.7), and pupils whose home language was not English achieved 174 points less than the pupils with English as a home language. In Grade 5, these pupils achieved $164.8(S E=19.0)$ points less. In Afrikaans, the difference in performance was less marked. Pupils who were second language Afrikaans speakers but who wrote the test in Afrikaans achieved lower scores, namely 79.7 points $(S E=24.1)$ and 78.4 points $(S E=21.3)$ less for Grades 4 and 5, respectively. Amongst the African indigenous languages for both Grade 4 and Grade 5 pupils, more than approximately $15 \%$ of the children received reading instruction in a language different to the home language. This difference in reading literacy achievement between those learning in their home language and those who learnt in a different African language was extremely small: $-6.3(S E=6.2)$ and -10.1 (SE = 7.3) for the two grades, respectively, and was not statistically significant. This result could be explained by the fact that African children, more often than not, are exposed to more than one indigenous language at a time both at home and in their respective communities. The ability, therefore, to understand more than one African language, along with the fact that African languages tend to be grammatically similar, might provide some explanation to the statistically insignificant difference found between home language and language different to home language performance for this group of pupils. 


\section{Discussion and conclusions}

PIRLS 2006 in South Africa is the first national study within an IEA study where so many languages of instruction have been assessed within one country and where the possibility exists for an extensive exploration of pupils' performance across such a wide variety of languages.

The results revealed that, firstly, the language in education policy has not been uniformly implemented nor advocated. The policy states that mother tongue education is compulsory in the Foundation Phase (Grades 1 to 3). A switch to either English or Afrikaans as language of instruction is prescribed in Grade 4. The implementation of this policy varies for different reasons. In some instances, African parents insist that their children are taught in English from the beginning, in Grade 1. Often, in an urban setting, it is not practical for a school to choose an indigenous language because of the variation among languages in the catchment area and the subsequent mix of pupils from different language backgrounds attending any one school.

Secondly, the vast majority of South African pupils are not proficient readers as measured by PIRLS, and Grade 4 and Grade 5 pupils' ability to switch from learning to read to reading to learn during the Intermediate Phase is diminished. South African reading performance does not compare with Grade 4 pupils internationally despite being on average 1 to 2 years older than their international counterparts. Thirdly, South African Grade 5 pupils achieve significantly higher scores than the Grade 4 pupils, which concurs with and would be expected from an additional year of instruction. However, this achievement varies across all languages and, with the exception of Sesotho (70 points), the smallest increases are found amongst the results of the pupils writing the test in African languages (ranging from 29 to 62 points) compared to English (65 points) and Afrikaans (79 points). Finally, the results reveal that, overall, no relationship could be found between the child's home language, the language of the test, and their performance in the reading test. However, significant differences were found when these were disaggregated to the individual language grouping level (English 174 and 168.8 points, Afrikaans 79.7 and 78.4 points, and African languages 6.3 and 10.1 points) for Grades 4 and 5, respectively.

The English mother tongue speakers in Grade 5 were the only group that attained an average above the international average score of $500(513, S E=13.6)$. This low average score attained by pupils writing in English in Grade 5 is a cause for great concern. The majority of pupils receiving instruction in English when English is not their mother tongue face grave challenges in education. The mean scale score of 284 $(S E=13.1)$ at Grade 4 level and of $349(S E=14.7)$ at Grade 5 level for this group (see Table 4) paint a bleak picture indeed of the level of education and achievement in South Africa, even when the increase between the two grade levels is taken into account. The implications for further education and the economic development and contribution of these pupils to the country are considerable and warrant immediate intervention. Considering that children in this group have had English as the language of instruction for 4 years, the effectiveness of the instruction and the quality of education in general is a matter of grave concern.

The extremely low performance of the children writing in African languages is not a surprise given the political heritage of the country. These children would most likely be in schools that are more poorly resourced, have less qualified teachers, and also 
have the most severely deprived socioeconomic circumstances. With the average mean score varying between 176 points (isiNdebele in Grade 4) to 289 (Sesotho in Grade 5), the children were at least 100 points below the groups of English and Afrikaans pupils. This large gap already at this stage of their schooling reflects the diversity of quality imposed on the education system historically. In the past 3 years, considerable efforts have been focused on closing this gap through intervention strategies (see Howie, 2008) and would not have been discernible in the PIRLS 2006. Other reasons for the poor state of reading literacy amongst pupils in South Africa are varied and are currently under investigation using the South African PIRLS 2006 data (Van Staden, 2006; Zimmerman, 2007). The low reading literacy levels may be a function of underresourcing, poor teaching practices, inadequate training in reading practices and lack of available resources for the indigenous languages, a lack of motivation to alter the situation, the oral tradition of the indigenous languages, the general role and influence of television, and a function of the time we live in, where instant gratification in so many aspects of life is propagated.

The most recent debates on language of learning in South Africa indicate that the Department of Education is reconsidering its policy on language of learning and is considering introducing all 11 official languages as languages of learning into the classroom for both primary and secondary schools. PIRLS 2006 is therefore very timely, and the additional national option included by the South African project team appears appropriate in its provision of significant information on the reading literacy levels of children in their first language as well as in English.

\section{References}

- 1. Admiraal, W., Westhoff, G. and De Bot, K. (2006) Evaluation of bilingual secondary education in The Netherlands: Students' language proficiency in English. Educational Research and Evaluation 12 , pp. 75-93.

- 2. Howie, S. J. (2003) Language and other background factors affecting secondary pupils' performance in mathematics in South Africa. African Journal of Research in Mathematics, Science and Technology Education 7 , pp. 1-20.

- 3. Howie, S. J. (2008) Measuring the health of the education system: Lessons from international studies for South Africa. Keynote address, presented at the Association for the Study of Evaluation and Assessment national conference Pretoria, South Africa

- 4. International Association for the Evaluation of Educational Achievement (2008) IDB Analyzer - (1.4.0.5) [Computer software]. Retrieved February 13, 2008, from http://www.iea.nl/iea_software.html

- 5. Leslie, L. and Allen, L. (1999) Factors that predict success in an early literacy intervention project. Reading Research Quarterly 34:4 , pp. 404-424.

- 6. Linnakylä, P., Malin, A. and Taube, K. (2004) Factors behind low reading literacy achievement. Scandinavian Journal of Educational Research 48:3 , pp. 231-249.

- 7. Martin, M. O., Mullis, I. V. S. and Kennedy, A. M. (2007) PIRLS 2006 technical report Boston College , Chestnut Hill, MA

- 8. Mullis, I. V. S., Kennedy, A. M., Martin, M. O. and Sainsbury, M. (2006) PIRLS 2006 assessment framework and specifications Boston College , Chestnut Hill, MA 
- 9. Strickland, D. S., Ganske, K. and Monroe, J. K. (2002) Supporting struggling readers and writers: Strategies for classroom intervention 3-6 Stenhouse, Portland, OR

- 10. Van Staden, S. (2006) Reading between the lines: Contributing factors that affect Grade 4 learner reading performance as measured across South Africa's 11 languages - PhD proposal, University of Pretoria, South Africa

- 11. Verhoeven, L. T. (1990) Acquisition of reading in a second language. Reading Research Quarterly 25:2 , pp. 90-114.

- 12. Zimmerman, L. (2007) Teaching at the transition point: Grade four educators' reading literacy teaching practices in South Africa University of Pretoria , South Africa - PhD proposal 